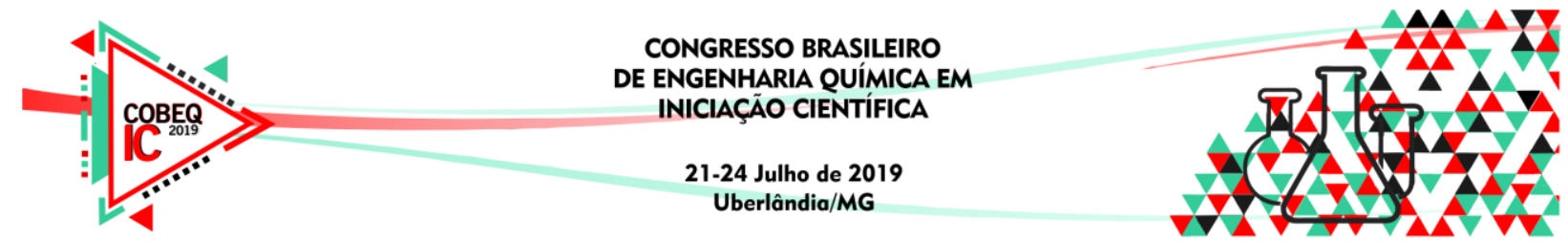

\title{
EXTRAÇÃO DE GELATINA DE RESÍDUO DE COURO CURTIDO AO CROMO POR DIFERENTES AGENTES ALCALINIZANTES
}

\author{
B. B. ZANELLA ${ }^{1}$, D. KREIN, D. Z. PIVA, W. I. ORSATO ${ }^{1}$ e A. DETTMER, \\ ${ }^{1}$ Universidade de Passo Fundo, Faculdade de Engenharia Química \\ E-mail para contato: 159005@upf.br
}

\begin{abstract}
RESUMO - A gelatina é um polímero obtido a partir da hidrólise do colágeno extraído da pele animal. É utilizada em indústrias de alimentos, farmacêuticas e fotográficas. Possui diversas características funcionais e é um alimento altamente nutritivo. O Brasil é um dos cinco maiores produtores de carne bovina e a produção de peles e couro atinge toneladas. Devido ao processo de curtimento, as indústrias de couro geram resíduos demasiados, que são de baixo valor comercial porém ricos em colágeno. Em vista disso, propõe-se uma alternativa para esses resíduos, a produção de gelatina. Neste trabalho, estudou-se a cinética de extração da gelatina de resíduos de couro curtido ao cromo. A extração ocorreu por meio de dois agentes alcalinizantes, óxido de cálcio e óxido de magnésio, durante sete horas em uma temperatura constante de $60^{\circ} \mathrm{C}$. A extração foi avaliada a partir do teor de proteína, nitrogênio e cromo. Observou-se que quanto maior o tempo de extração, maior o teor de cromo e de proteína. Melhores resultados foram obtidos com o óxido de magnésio.
\end{abstract}

\section{INTRODUÇÃO}

O cuidado com o meio ambiente é uma das preocupações mundiais, principalmente para empresas que geram resíduos que podem provocar degradação ambiental. A fim de garantir a sustentabilidade, as empresas buscam meios de reduzir esses impactos.

No segundo trimestre de 2018, foram curtidas 7.895.896 peças de couro pelo método de curtimento ao cromo no Brasil de acordo com o IBGE (2018). Mostrando assim, o potencial brasileiro quanto à indústria de couros. Segundo Zhao (2009), uma tonelada de pele crua gera apenas $200 \mathrm{~kg}$ de couro. Em contrapartida, são gerados $600 \mathrm{~kg}$ de resíduos sólidos, provenientes de etapas que compõe o processamento.

Com vista em reduzir a geração de resíduos, uma das alternativas é a extração de gelatina por meio da hidrólise do colágeno proveniente do couro. Conforme Ferreira (2003), são diversas possibilidades de reutilização do resíduo, como adsorventes para o tratamento de efluentes e fertilizantes e ainda é possível a utilização do resíduo para a produção de filmes poliméricos para a cobertura de solos.

A extração da gelatina através da hidrólise do resíduo do couro é dada por meio de diferentes agentes alcalinizantes, com resultados diferentes. O propósito do trabalho é analisar a cinética da extração de gelatina, utilizando como agentes alcalinizantes óxido de cálcio e óxido de magnésio e encontrar o tempo ideal, na qual se obtenha a maior quantidade de proteínas e a menor de cromo. 


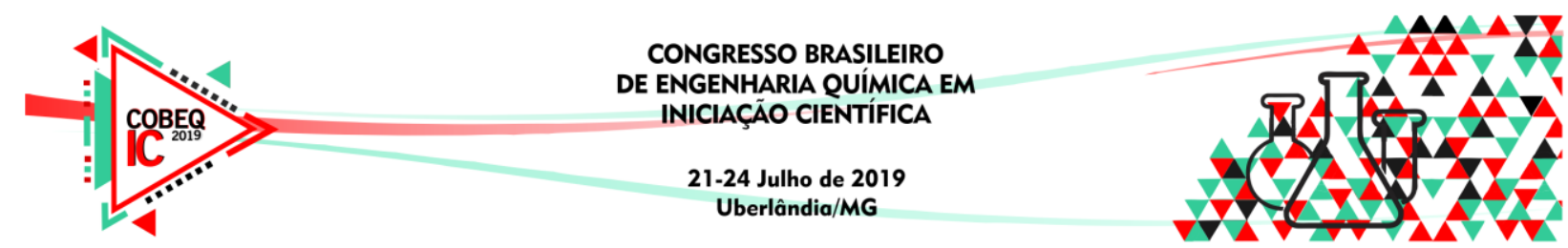

\section{METODOLOGIA}

\subsection{Extração de Gelatina}

A gelatina foi extraída segundo o método descrito por Dettmer et al. (2014). Foi realizada a hidrólise do material usando $1 \mathrm{~g}$ de óxido de magnésio $(\mathrm{MgO})$ e $1 \mathrm{~g}$ de óxido de cálcio $(\mathrm{CaO})$ como agentes alcalinizantes, $125 \mathrm{~mL}$ de água destilada e $25 \mathrm{~g}$ de resíduo de couro. As amostras de RCCC (resíduos de couro curtido ao cromo), foram caracterizadas de acordo com as normas da American Society for Testing and Material (ASTM) descritas em cada tópico.

A extração da gelatina decorreu durante sete horas à $60^{\circ} \mathrm{C}$ e $150 \mathrm{rpm}$, em uma Incubadora Refrigerada com Agitação TE-421 da Tecnal. Ao longo desse tempo, foram retiradas amostras para caracterização a cada sessenta minutos. Em um intervalo de 1 hora, 4 horas e 7 horas foram retiradas amostras para realização da caracterização do teor de Nitrogênio Total Kjeldal (NTK). Determinou-se a quantidade de NTK, proteína, cinzas, cromo, $\mathrm{pH}$. Os procedimentos foram executados nos laboratórios de Aulas Práticas, Processos Químicos, Biotecnologia e Bioprocessos e de Físico-Química da UPF. Os experimentos foram realizados em quintuplicata.

\subsection{Caracterização da Gelatina}

Teor de cromo: A determinação do cromo no RCCC foi realizada pelo método de titulometria, conforme ASTM D2807-1993. Foram usados ácidos para promover a oxidação do cromo da amostra. A solução foi titulada com tiossulfato de sódio. O teor de cromo na amostra é obtido pela Equação 1:

$$
\mathrm{Cr}_{2} \mathrm{O}_{3} \%=\text { V.C } .0,02533 \cdot\left(100 / m_{p}\right)
$$

Sendo,

$\mathrm{V}=$ Volume de tiossulfato de sódio utilizado na titulação $(\mathrm{mL})$;

$\mathrm{C}=$ Concentração de tiossulfato de sódio $(\mathrm{mol} / \mathrm{L})$;

$\mathrm{m}_{\mathrm{P}}=$ Massa da amostra pesada $(\mathrm{g})$;

A determinação do cromo presente na gelatina deu-se através do método da difenilcarbazida, descrito pela norma, ASTM D1687-1992, a partir do qual o cromo está determinado na forma de cromo hexavalente. Preparou-se uma curva padrão para fornecer uma equação da reta.

pH: A determinação do $\mathrm{pH}$ das amostras de RCCC seguiu o método da ASTM D28101972. Realizou-se a determinação por um pHmetro DM-22 da Digimed.

Nitrogênio Total Kjeldahl: A determinação do Nitrogênio Total Kjeldahl deu-se pelo método ASTM D2868-1996, e se resume nas etapas de digestão, destilação e titulação, foram utilizados ácidos para essas etapas e o destilador de nitrogênio TE-036/1 da Tecnal. A quantidade de nitrogênio foi averiguada pela Equação 4: 


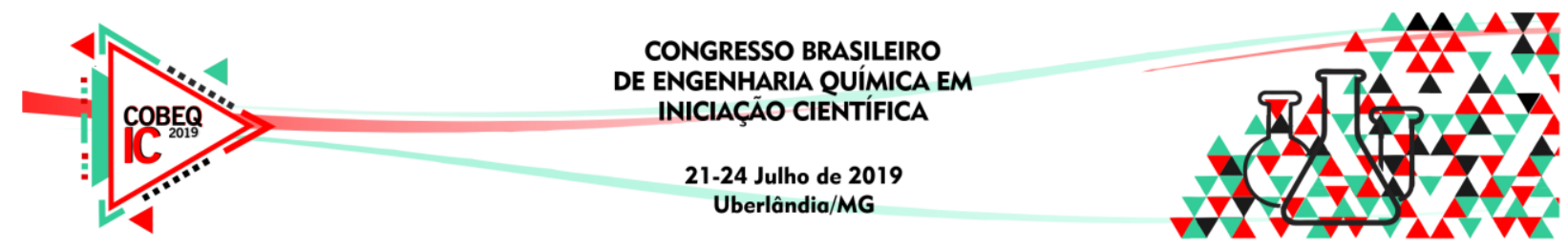

$$
\text { Nitrogênio }(\%)=\left[\left(V_{\alpha}-V_{b}\right) \cdot N \cdot 0,01401\right] / m_{p} \cdot 100
$$

Sendo,

$\mathrm{Va}=$ Volume de ácido requerido na titulação $(\mathrm{mL}) ;$

$\mathrm{Vb}=$ Volume de ácido requerido no branco $(\mathrm{mL})$;

$\mathrm{N}$ = Normalidade do ácido padrão;

$\mathrm{mP}=$ Massa da amostra $(\mathrm{g})$;

Método de Lowry: O método utilizado foi o método descrito por Lowry (1951), sendo o mais utilizado para a determinação de proteínas. É utilizado o reagente de Folin-Ciocalteau, que sofre uma redução quando reage com proteínas, na presença do catalisador $\mathrm{Cu}^{+2}$ e produz um composto com absorção máxima em $760 \mathrm{~nm}$, utilizou-se o espectrofotômetro da Tecnal.

\section{RESULTADOS}

Mediante a extração da gelatina presente no resíduo de couro, as análises propostas foram realizadas.

Os resultados da caracterização das amostras, podem ser visualizados na Tabela 1.

Tabela 1 - Caracterização das amostras de gelatina extraída com diferentes agentes alcalinizantes

\begin{tabular}{|l|c|c|c|c|}
\hline & \multicolumn{2}{|c|}{ MgO } & \multicolumn{2}{c|}{ CaO } \\
\hline \multicolumn{1}{|c|}{ Análises } & $\mathbf{4 ~ h}$ & $\mathbf{7 ~ h}$ & $\mathbf{4 ~ h}$ & $\mathbf{7 ~ h}$ \\
\hline $\begin{array}{l}\text { Nitrogênio Total Kjeldahl } \\
(\%)\end{array}$ & 0,123 & 0,208 & 0,124 & 0,203 \\
\hline $\begin{array}{l}\text { Proteína de Lowry } \\
(\mathrm{mg} / \mathrm{L})\end{array}$ & 4,106 & 5,871 & 3,562 & 4,219 \\
\hline $\begin{array}{l}\text { Teor de Cromo (mg/L) } \\
\text { Proteína de Lowry / } \\
\text { Nitrogênio Total Kjeldahl }\end{array}$ & 0,184 & 0,308 & 0,538 & 0,805 \\
\hline
\end{tabular}

Comparando as extrações com os dois agentes alcalinizantes, pode-se perceber que, não há grandes diferenças em questão de quantidade de nitrogênio. Mas quando comparamos a quantidade de proteínas, nota-se que o óxido de magnésio tem melhores resultados que o óxido de cálcio.

O óxido de cálcio por ter poder de hidrólise mais forte, acaba degradando a proteína e também solubilizando o cromo, promovendo um maior arraste para a gelatina. 


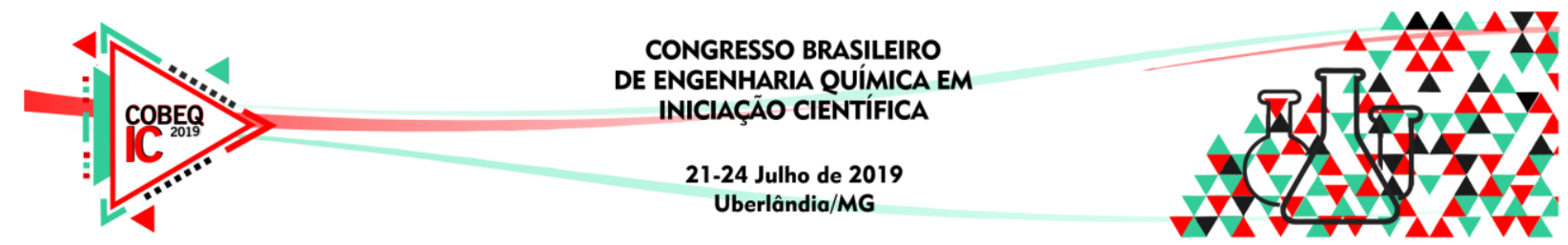

Quando analisamos a quantidade de proteína pelo método de Lowry, pode-se verificar que o melhor momento de extração seria no tempo de 4 horas, pois o valor de proteínas é alto, e o arraste de cromo é baixo.

As melhores concentrações de proteína e nitrogênio estão nas 7 horas de extração com o óxido de magnésio. O resíduo de couro ficou mais tempo hidrolisando, sendo assim, maior formação de substâncias com nitrogênio em sua composição.

A relação cromo e proteína com o óxido de magnésio, não segue um aumento ou diminuição contínua. As oscilações são muito grandes, assim, não atingindo um padrão. Analisando o gráfico da Figura 1, nota-se uma leve decaída na linha tendência. O agente é considerado melhor pois, no final de 7 horas haverá menor arraste de cromo, mas ainda assim uma boa quantidade de proteínas.

Figura 1 - Relação Cromo/Proteína com Óxido de Magnésio.

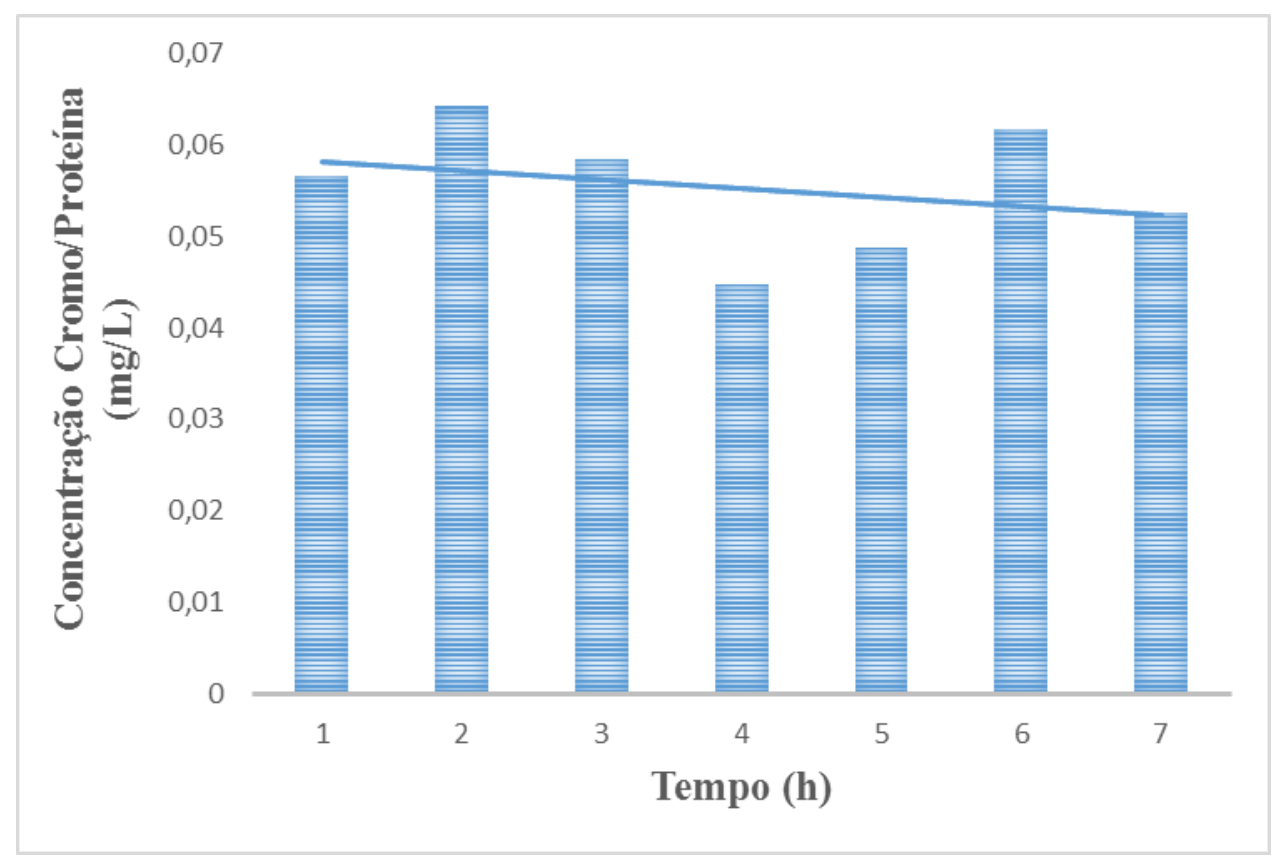

Na relação cromo e proteína com o agente óxido de cálcio apresentado na Figura 2, percebe-se a conformidade das barras, seguindo uma tendência. $\mathrm{O}$ óxido de cálcio não é considerado o melhor agente alcalinizante, pois da mesma forma que aumenta a concentração de proteína, também há o aumento da concentração de cromo, e o que queremos para a gelatina final é a menor quantidade de cromo arrastado.

Figura 2 - Relação Cromo/Proteína com Óxido de Cálcio. 

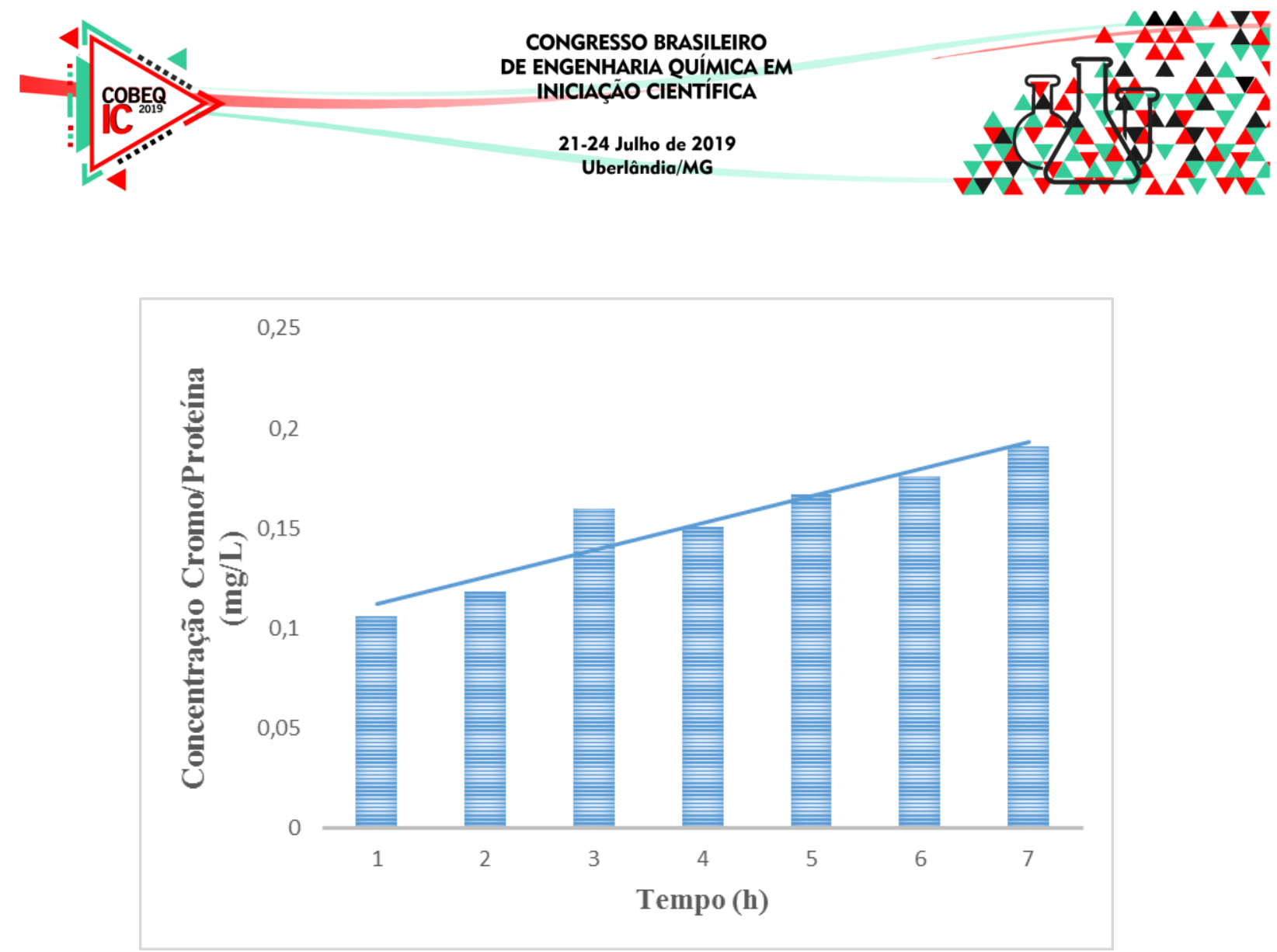

\section{CONCLUSÃO}

Pode-se concluir que, o agente alcalinizante com melhores resultados é o óxido de magnésio, pois possui um menor arraste de cromo e maior quantidade de proteínas, quando comparado com o óxido de cálcio.

\section{REFERÊNCIAS}

DETTMER, A et al. Produção de filmes poliméricos a partir de amido de milho e de gelatina extraída de resíduos de couro curtido ao cromo. In: Congresso brasileiro de polímeros, 13., 2015, Natal. Congresso brasileiro de polímeros. Natal: Cnpq, 2015. p. 1 - 5.

FERREIRA, Mirele F. Extração e caracterização de gelatina proveniente de subprodutos do frango: pés. 2013. 48 f. Trabalho de Conclusão de Curso (Engenharia de Alimentos), Universidade Tecnológica Federal do Paraná. Campo Mourão, 2013.

LOWRY, O. H.; ROSEBROUGH, N. J.; FARR, A. L; RANDALL, R. J. Protein measurement with the Folin-Phenol reagent. The Journal of Biological Chemestry, v. 193, p; 265-276, 1951.

MORGAN, Katharine E.. American Society for Testing and Materials (ASTM). Disponível em: <https://www.astm.org/>. Acesso em: 11 set. 2018. 


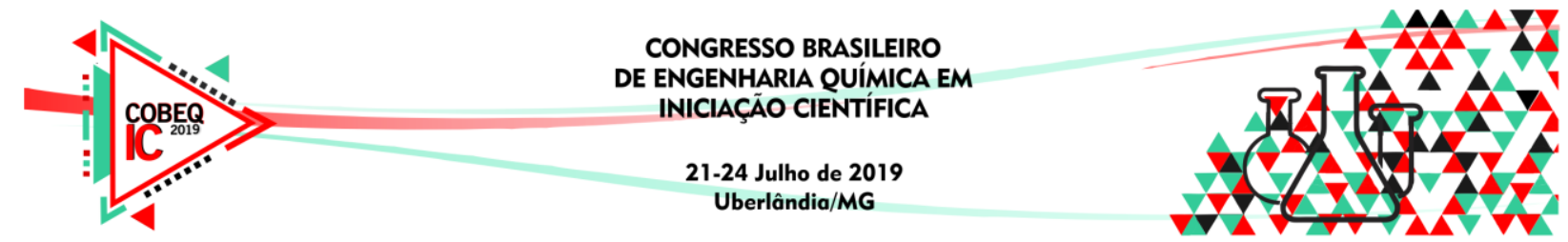

MORGAN, Katharine E.. ASTM D2807 - 17 Standard Test Method for Chromic Oxide in Leather (Perchloric Acid Oxidation). Disponível em: <https://www.astm.org/Standards/D2807.htm>. Acesso em: 11 set. 2018.

MORGAN, Katharine E.. ASTM D1687 - 17 Standard Test Methods for Chromium in Water. Disponível em: <https://www.astm.org/Standards/D1687.htm>. Acesso em: 11 set. 2018.

MORGAN, Katharine E.. ASTM D2810 - 13 Standard Test Method for $p H$ of Leather. Disponível em: <https://www.astm.org/Standards/D2810.htm>. Acesso em: 11 set. 2018.

MORGAN, Katharine E.. ASTM D2868 - 17 Standard Test Method for Nitrogen Content (Kjeldahl) and Hide Substance Content of Leather, Wet Blue and Wet White. Disponível em: <https://www.astm.org/Standards/D2868.htm>. Acesso em: 11 set. 2018.

ZHAO, S.; ZHANG, Mi; LI, G.; LU, W. Preparation and characterization of alkali-soluble collagen from pigskin shavings. Journal of the American Leather Chemists Association, China, v. 104, p. 344-350, mai. 2009. 